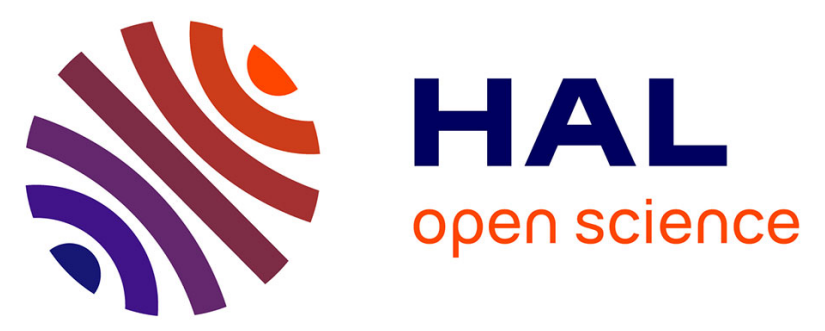

\title{
Executive functions in schizophrenia aging: Differential effects of age within specific executive functions
}

Flavien Thuaire, Fabien Rondepierre, Elisabeth Bacon, Guillaume T. Vallet, Isabelle Jalenques, Marie Izaute

\section{> To cite this version:}

Flavien Thuaire, Fabien Rondepierre, Elisabeth Bacon, Guillaume T. Vallet, Isabelle Jalenques, et al.. Executive functions in schizophrenia aging: Differential effects of age within specific executive functions. Cortex, 2020, 125, pp.109-121. 10.1016/j.cortex.2019.12.003 . hal-02983739

\section{HAL Id: hal-02983739 \\ https://hal.science/hal-02983739}

Submitted on 4 Nov 2020

HAL is a multi-disciplinary open access archive for the deposit and dissemination of scientific research documents, whether they are published or not. The documents may come from teaching and research institutions in France or abroad, or from public or private research centers.
L'archive ouverte pluridisciplinaire HAL, est destinée au dépôt et à la diffusion de documents scientifiques de niveau recherche, publiés ou non, émanant des établissements d'enseignement et de recherche français ou étrangers, des laboratoires publics ou privés. 
1 Title: Executive functions in schizophrenia aging: differential effects of age

2 within specific executive functions

3

4

5

6

7

8

9

10

\section{Authors and affiliations.}

Flavien Thuaire ${ }^{\mathrm{a}}$, Fabien Rondepierre ${ }^{\mathrm{b}}$, Elisabeth Bacon ${ }^{\mathrm{c}}$, Guillaume T. Vallet ${ }^{\mathrm{a}}$, Isabelle Jalenques ${ }^{\mathrm{d}}$, Marie Izaute $^{\mathrm{a} 1}$

${ }^{\text {a }}$ Université Clermont Auvergne, CNRS, LAPSCO, F-63037 Clermont-Ferrand, France.

${ }^{\mathrm{b}}$ Service de Psychiatrie de l'Adulte A et Psychologie Médicale, Centre Mémoire de Ressources et de Recherche, CHU Clermont-Ferrand, Clermont-Ferrand, France.

${ }^{c}$ INSERM U-1114, Fédération de Médecine Translationnelle de Strasbourg (FMTS), CHU de Strasbourg, Université de Strasbourg, France.

${ }^{\mathrm{d}}$ Service de Psychiatrie de l'Adulte A et Psychologie Médicale, Centre Mémoire de Ressources et de Recherche, CHU Clermont-Ferrand, Institut de Psychiatrie-GDR 3557, Université Clermont Auvergne, Clermont-Ferrand, France.

${ }^{1}$ Corresponding author: Marie Izaute LAPSCO, UMR CNRS 6024, 34 avenue Carnot, 63037 ClermontFerrand, France

Telephone: + 33473406255 - Fax: + 33473406482

E-mail: marie.izaute@uca.fr 
30

\section{Abstract}

There are common cognitive and brain abnormalities in schizophrenia and healthy aging which may cumulate in schizophrenia aging. However, the course of executive deficits in late-life schizophrenia is still controversial as it remains unclear whether schizophrenia patients show accelerated aging. The use of specific models of executive functions might help to shed new lights on this issue. The aim of this study was then to determine how each of the four specific executive functions (shifting, updating, inhibition and access to long-term memory) is affected by aging in schizophrenia compared to healthy aging.

20 younger (age 18-34), 17 middle-aged (age 35-49) and 25 older (age 59-76) schizophrenia patients and 62 healthy comparison participants matched for gender, age and education performed a neurocognitive battery evaluating the four specific executive functions.

Schizophrenia patients performed worse than comparison participants on shifting, updating and access, whereas inhibition appeared preserved. Age affected the four functions with increased degradation of shifting and access in schizophrenia patients, whereas updating and inhibition showed a normal decline with age.

These results suggest a vulnerability of prefrontal and cingulate cortexes in schizophrenia aging. Moreover, as age affected the specific executive functions differently, remediation programs should be adapted to older patients. Models of specific executive functions are useful for understanding the complexity of cognition in schizophrenia and its course during later life so that healthcare can be adapted accordingly.

Key Words: Schizophrenia; Adulthood; Aging; Executive functions; Miyake's model. 


\section{Introduction:}

Cognitive impairment is a core feature of schizophrenia and affects most of the cognitive domains (Heinrichs \& Zakzanis, 1998; Mesholam-Gately, Giuliano, Goff, Faraone, \& Seidman, 2009). Among those, executive functioning deals with problems of control and coordination which may emerge when the separate processes must work together (Logan, 1985). They are implicated in adapting behavior to diverse situations, creating a plan, initiating its execution, and persevering until its completion, and they mediate our ability to organize our thoughts in a goal-directed way (Jurado \& Rosselli, 2007). Schizophrenia is the clinical pathology where the largest executive functions deficits are found (Snyder, Miyake, \& Hankin, 2015). Since executive functions affect performance in a wide variety of cognitive variables (Kerns, Nuechterlein, Braver, \& Barch, 2008; Salthouse, Atkinson, \& Berish, 2003), their impairment would underlie other cognitive impairments in schizophrenia (Nathaniel-James, Brown, \& Ron, 1996). It is therefore of a particular interest to focus on these functions in schizophrenia to adapt remediation programs accurately.

Moreover, recent findings suggest that schizophrenia is a neurodevelopmental disorder with cognitive impairments exhibited prior to the onset of the pathology (Meier et al., 2014; Sheffield, Karcher, \& Barch, 2018). Cortical dysfunctions are observed during executive tasks including reduced activations in the prefrontal cortex, anterior cingulate cortex and thalamus (Minzenberg, Laird, Thelen, Carter, \& Glahn, 2009). Recent studies also observed structural deterioration of white matter in networks involving the prefrontal cortex (Orellana \& Slachevsky, 2013; Wagner et al., 2015). Thus, despite the heterogeneity of the findings concerning cortical dysfunctions in schizophrenia, impairment in prefrontal functioning, which is historically linked to executive functioning (Luria, 1966; Shallice, 1982), is consistently observed.

Executive functions are composed of multiple sub-functions which may be grouped together in three specific functions that are independent of each other but also correlated to the general concept of executive functioning (Miyake et al., 2000). These three functions are the ability to shift back and 
forth between multiple tasks, operations or mental sets (shifting), the ability to include relevant new information in working memory and suppress irrelevant information (updating), and the ability to cancel prepotent but irrelevant behavior (inhibition). Based on this model, it has been shown that these three specific functions are impaired in cognitive aging (Adrover-Roig, Sesé, Barceló, \& Palmer, 2012) and that their study helps describe the relations between age and cognitive functions more accurately. Indeed, updating and inhibition mediated performance in autobiographical memory (Piolino et al., 2010), whereas inhibition and shifting were involved in prospective memory performance (Schnitzspahn, Stahl, Zeintl, Kaller, \& Kliegel, 2013). Although this model is the most commonly used, the authors acknowledge that it is not comprehensive and other factors may be added (N. P. Friedman \& Miyake, 2017). Accordingly, Some authors (Fisk \& Sharp, 2004) extended Miyake et al.'s work and found a fourth specific executive function, labeled "access", which reflects the efficiency of access to long-term memory. The authors observed that access was the only specific executive function not affected by age.

Models showing multiple independent executive processes are of interest to explain cognitive heterogeneity in schizophrenia (Reichenberg \& Harvey, 2007). Thus, several experiments used tests that measure these specific functions in schizophrenia and found deficits in shifting (Ceaser et al., 2008; Tyson, Laws, Roberts, \& Mortimer, 2004), updating (Culbreth, Westbrook, \& Barch, 2016; Zanelli et al., 2010), inhibition (Laurenson et al., 2015; Westerhausen, Kompus, \& Hugdahl, 2011) and access (Rossell, 2006; Szöke et al., 2005). However, only a few studies about schizophrenia included at least the three functions described by Miyake et al. (2000). Some studies (Chan, Chen, \& Law, 2006; Donohoe, Corvin, \& Robertson, 2006; Wongupparaj, Kumari, \& Morris, 2015) found significant differences between patients and comparison participants with respect to measures of the three functions. Another study (Raffard \& Bayard, 2012) also found group differences with each specific function and their results revealed greater heterogeneity in schizophrenia than in controls. Some patients presented no deficits, some had deficits on all measures, and others were impaired 
only with regard to one or two specific executive functions. Furthermore, one study (Rabanea-Souza et al., 2016) found that impaired shifting and updating appear to be predictors of schizophrenia diagnosis, whereas preservation of inhibition and updating seem to be predictors of symptom remission. Thus, this research points to the usefulness of assessing specific executive functions to understand executive functioning in schizophrenia. However, to the best of our knowledge, no study has explored specific executive functions in older schizophrenia patients, despite specific executive functions being a good indicator of cognitive performance among normal aging. In fact, reduced executive performance in healthy older participants (Andrés \& Van der Linden, 2000) is a predictor of the impairment of other processes such as verbal memory (Bryan, Luszcz, \& Pointer, 1999; Taconnat et al., 2009). Although it seems executive functions alone do not account for all agerelated deficits (Cona, Arcara, Amodio, Schiff, \& Bisiacchi, 2013; Verhaeghen \& Cerella, 2002), it would seem they are particularly implicated in the most difficult tasks where older participants show a drop in performance (Cona et al., 2013; Silver, Goodman, Gur, Gur, \& Bilker, 2011; Verhaeghen \& Cerella, 2002).

The cognitive deficits appeared even before the onset of schizophrenia (Meier et al., 2014; Sheffield et al., 2018), and its decline in late life is strongly linked to functional competences (Harvey, Parrella, White, Mohs, \& Davis, 1999; Kalache et al., 2015). Yet, despite the growing number of older patients with schizophrenia (C. Cohen et al., 2008; Lee et al., 2018), their course during late adulthood remains unclear because of the lack of studies investigating this issue (Herold, Schmid, Lässer, Seidl, \& Schröder, 2017; Rajji \& Mulsant, 2008) and because normal aging is also associated with executive decline (Cona et al., 2013; Silver et al., 2011; Verhaeghen \& Cerella, 2002). Moreover, cognitive changes during healthy aging are "surprisingly similar to the changes that are seen in people with schizophrenia" (Harvey \& Rosenthal, 2018). This similarity also involve brain anatomy because grey and white matter atrophy in prefrontal regions are reported in both healthy aging (Teipel et al., 2010) and schizophrenia (Orellana \& Slachevsky, 2013; Zierhut et al., 2013). It 
is therefore possible that aging has more deleterious effects in schizophrenia patients than in healthy people. Thus, it is of special interest to ascertain whether cognitive deficits in schizophrenia patients increase more with aging than is the case with healthy participants. This knowledge is necessary to adapt treatments and cognitive remediation programs for older patients. Schizophrenia patients show accelerated physical aging (Jeste, Wolkowitz, \& Palmer, 2011), including for their brain (Schnack et al., 2016; Sheffield et al., 2016) compared to healthy controls of the same age. Studies are less consistent, however, concerning neurocognition which is linked to adaptive functioning (Green, 2016; Harvey et al., 1999), quality of life (Mohamed et al., 2008), and social and everyday living skills (Evans et al., 2003; Kalache et al., 2015; McClure et al., 2007). Some authors observed accelerated aging only with executive functions (Fucetola et al., 2000; Herold et al., 2017), whereas others indicated that it did not affect executive functions at all, but processing speed and verbal learning (Loewenstein, Czaja, Bowie, \& Harvey, 2012), or visuo-spatial functions (Stirling et al., 2003) instead. The results of a meta-analysis failed to report accelerated aging (Irani, Kalkstein, Moberg, \& Moberg, 2011) on several functions, including executive functions, and the authors of another study even observed a normalization of cognition with aging in schizophrenia patients (Irani et al., 2012). Several factors may account for these controversial results, including the kind of tasks used to measure cognition, whether or not patients are institutionalized (Bowie, Reichenberg, McClure, Leung, \& Harvey, 2008), task difficulty (Knapp, Viechtbauer, Leonhart, Nitschke, \& Kaller, 2017) and, more critically, the age of the older patients included in the study (J. I. Friedman et al., 2001; Rajji \& Mulsant, 2008).

We aimed to determine whether a particular specific executive function could be a sensitive indicator of accelerated aging in schizophrenia. Based on previous studies, we hypothesized that patients' performance would be lower in all four executive functions (shifting, updating, inhibition and access), and that younger participants would perform better than older participants in all executive functions except for "access". Finally, we surmised that depending on the specific 
executive function considered, aging would show differential effects between schizophrenia patients and comparison participants. More precisely, according to previous studies showing accelerated aging in tasks assessing shifting (Fucetola et al., 2000; Herold et al., 2017), we hypothesized that accelerated aging would occur at least in this specific function. However, concerning the other specific functions, due to the lack of data in the literature about cognitive aging in schizophrenia we cannot postulate precise hypotheses.

\section{Methods and material}

\subsection{Participants}

We report how we determined our sample size, all data exclusions (if any), all data inclusion/exclusion criteria, whether inclusion/exclusion criteria were established prior to data analysis, all manipulations, and all measures in the study. This study was conducted in accordance with ethical standards and had the approval of the local ethics committees (EudraCT 2010-A0085732 and PRI 2000, HUS $\mathrm{N}^{\circ} 2326$ ). Before the investigation started, all the participants provided written informed consent after receiving a full explanation about the study. The participants were 62 clinically-stable outpatients with schizophrenia recruited from the Psychiatric Department of the University Hospital. The following inclusion/exclusion criteria were established prior to data analysis, and all manipulations and measurements performed in the study. According to the consensus opinion of their current psychiatrist and a senior psychiatrist on the research team, all of the patients met the criteria for schizophrenia as set out in the Diagnostic and Statistical Manual of Mental Disorders -IV-TR. Patients with any current co-morbid neurologic or psychiatric disorder, including alcohol or substance abuse or dependence, were not included. Their psychiatric symptoms were assessed according to the Positive And Negative Symptoms Scale (PANSS) (Kay, Fiszbein, \& Opler, 1987). Anxiety and depression were screened using the Hospital Anxiety and Depression Scale (HADS) (Zigmond \& Snaith, 1983). Verbal intelligence quotient (IQ) was evaluated using 
vocabulary and arithmetic tests taken from the short version of the Wechsler Adult Intelligence Scale, revised (WAIS-R) (Silverstein, 1982). Patients received stable doses of psychotropic medication for at least 4 weeks. In addition, 62 healthy comparison participants who matched the patients in terms of age, gender and education as recommended (Fioravanti, Bianchi, \& Cinti, 2012), were recruited from the community. None of these participants had a known neurological or psychiatric affection or was currently suffering or had suffered in the past from alcohol or substance abuse or dependence. The participants were divided into three age groups: Young participants were under 35, middle-aged participants were between 35 and 49, and older participant were over 59. These age groups were chosen according to previous research (Fucetola et al., 2000) with the aim of increasing the age of older participants. In order to more clearly distinguish the effect of age, participants between the ages of 50 and 59 were not recruited. Our sample size was based on a power analysis showing that 124 participants allow $85 \%$ power for detecting an effect size of .3 with an alpha of .05. These criteria go beyond those of a recently published study (Facchin, Sartori, Luisetti, De Galeazzi, \& Beschin, 2019). Table 1 presents the demographical, clinical and descriptive statistics of the group comparison data.

Table 1. Demographic characteristics of patients with schizophrenia and comparison participants by age group (standard deviations shown in brackets).

\begin{tabular}{|c|c|c|c|c|c|c|}
\hline & \multicolumn{3}{|c|}{ Schizophrenia patients } & \multicolumn{3}{|c|}{ Healthy comparison participants } \\
\hline & $\begin{array}{l}\text { Young } \\
n=20\end{array}$ & $\begin{array}{c}\text { Middle aged } \\
n=17\end{array}$ & $\begin{array}{l}\text { Older } \\
\mathrm{n}=25\end{array}$ & $\begin{array}{c}\text { Young } \\
n=20\end{array}$ & $\begin{array}{l}\text { Middle aged } \\
\quad \mathrm{n}=17\end{array}$ & $\begin{array}{l}\text { Older } \\
\mathrm{n}=25\end{array}$ \\
\hline Men/women & $13 / 7$ & $7 / 10$ & $15 / 10$ & $13 / 7$ & $7 / 10$ & $15 / 10$ \\
\hline Age (years) ${ }^{b}$ & $28.3(4.3)$ & $42.8(4.4)$ & $63.4(4.0)$ & $28.9(4.3)$ & $42.7(4.0)$ & $63.7(3.9)$ \\
\hline Education level & $11.0(1.4)$ & $12.2(3.2)$ & $11.0(3.6)$ & $11.6(1.2)$ & $12.1(2.9)$ & $10.9(3.3)$ \\
\hline PANSS total & $65.8(19.8)$ & $72.5(19.8)$ & $64.0(16.9)$ & & & \\
\hline PANSS Positive score & $15.4(4.3)$ & $14.4(4.6)$ & $13.6(6.0)$ & & & \\
\hline PANSS Negative score & $17.5(6.9)$ & $20.6(9.0)$ & $18.2(6.2)$ & & & \\
\hline
\end{tabular}


PANSS General

psychopathology

$32.9(10.9) \quad 37.4(9.3) \quad 32.3(7.9)$

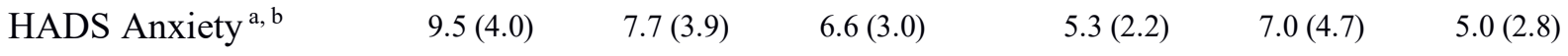

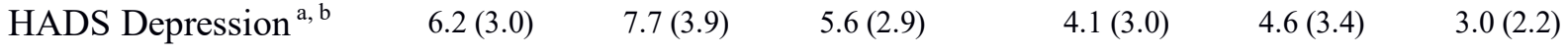

Verbal IQ $^{\mathrm{a}, \mathrm{b}} \quad 83.2(18.5) \quad 85.9(16.3) \quad 89.8(12.1) \quad 90.7(14.8) \quad 94.8(11.9) \quad 108.9(12.9)$

Notes. PANSS= Positive And Negative Symptom Scale; HADS= Hospital Anxiety and Depression Scale; IQ= Intelligence Quotient. a significant group difference between patients and comparison participants

${ }^{\mathrm{b}}$ significant age difference

\subsection{Material}

Neuropsychological tests were selected according to the framework devised by Miyake et al (Miyake et al., 2000) which distinguishes three specific executive functions (shifting, updating and inhibition) with the addition of the efficiency of access to long-term memory (Fisk \& Sharp, 2004). Two tests were used for each specific function. No part of the study procedures was pre-registered prior to the research being conducted. Computerized tasks used in this article (Number-letter task and Self-Ordered Pointing Task) are available at: https://osf.io/2w34k/

The scores used in the analyses consisted of:

\subsubsection{Shifting tasks:}

Plus-minus task (Jersild, 1927; Spector \& Biederman, 1976): This task consisted of three lists of two digit numbers. Participants were instructed to add 3 to all the numbers in the first list and to write down the result, to subtract 3 in the second list and, finally, to alternate between adding and subtracting 3 in the third list. The shift cost was calculated as the difference between the time taken to complete the third list and the average of the time taken for the first and second lists: T3 - [(T2 + T1)/2] (Miyake et al., 2000).

Number-letter task (Rogers \& Monsell, 1995): This task was computerized. A number-letter pair was presented in one of four quadrants on the screen. Participants were instructed to indicate whether the number was odd or even when the pair was presented in one of the upper quadrants, 
and whether the letter was a consonant or a vowel when the pair was presented in either of the bottom two quadrants. The pairs were all presented in the upper quadrants for the first block of 32 items, in the bottom two quadrants for the second block and randomly in any of the quadrants in the last block of 32 items. The shift cost was calculated in the same way as in the plus-minus test: T3 [(T2 + T1) / 2] (Miyake et al., 2000).

\subsubsection{Access tasks:}

Verbal fluency: Two verbal fluency tasks were assessed, phonemic fluency (Letter P) and semantic fluency (category "animals"). The score was the number of correct words within 60 seconds.

\subsubsection{Updating tasks:}

N-back task (Clarys, Bugaiska, Tapia, \& Baudouin, 2009; Perrotin, Belleville, \& Isingrini, 2007): A list of 30 letters was read out to the participants, who were instructed to say aloud (yes/no) whether the current letter was the same as one of the three previous letters. To simplify the instructions for the older patients, participants were asked to compare the current letter not with one letter occurring earlier in the sequence but with the 3 previous letters. The next letter was read after the participant's response. The score was the number of correct answers (hits and correct rejections). As there was no 0-back control condition, working memory performance cannot be separated from lower order functions.

Self-Ordered Pointing Task (Petrides \& Milner, 1982): This computerized task consisted of 16 drawings presented together 16 times but each time with a different organization. Participants were instructed to choose a different drawing in each presentation, the aim being to select each of the 16 drawings during the 16 presentations. The score was the number of different drawings selected.

\subsubsection{Inhibition tasks:}


Stroop color word task (SCWT) (Stroop, 1935), card version: Two subtests of the SCWT were used.

In the color naming baseline condition, participants were instructed to name the color of crosses (XXXX) within 45 seconds, and in the color-word condition, they had to name the color of the ink of words denoting a color within 45 seconds. Items were presented on a sheet of paper. To reduce the potential bias of patients' cognitive slowing, we used the following interference score ( $\mathrm{Li} \&$ Bosman, 1996): (Baseline - color word)/Baseline.

Hayling sentence Completion Test (HSCT) (Burgess \& Shallice, 1996): In part A, participants were instructed to complete orally 15 sentences read by the experimenter by providing the appropriate final word. In part B, they had to complete 15 new sentences with a word that had no semantic link with the sentence. The scores were the time taken to complete part B and the number of errors in part B.

\subsection{Data analyses}

Data used in this article are available at: https://osf.io/2w34k/

Not all participants completed all the tests: 5 (4\%) didn't complete the plus minus test (3 young patients, 1 middle-aged patient and 1 older patient), $1(0.8 \%)$ the n-back test ( 1 older patient) and $10(8 \%)$ the HSCT (1 young patient, 1 middle-aged patient, 6 older patients and 2 older comparison subjects). The missing data were replaced using Multiple Imputation by Chained Equations $(\mathrm{MICE})^{1}$.

In order to test the effects of Age (young, middle or old) and Group (healthy comparison participants vs. schizophrenia patients) and the interaction between Age and Group on executive functions, we

\footnotetext{
${ }^{1}$ MICE is a very flexible procedure with several advantages over other missing data approaches (Azur, Stuart, Frangakis, \& Leaf, 2011). As MICE operates according to the assumption that missing data are missing at random, we tested our dataset with Little's Missing Completely At Random (MCAR) test. The result $\left(\chi^{2}=27.58 ; \mathrm{df}=21 ; p=.153\right.$ ) indicates that the null hypothesis that data are missing completely at random cannot be dismissed. We therefore created 40 imputed datasets as recommended (Azur et al., 2011), and the means of these datasets were used to replace missing data. Statistical analyses were also run without replacing missing data and yielded the same results.
} 
computed Z-scores for each task and then calculated the means between the two tests within each of the four executive domains (shifting, updating, inhibition and access) to create a composite index for these cognitive abilities ${ }^{2}$. We then ran separate Analyses Of Variance (ANOVAs) on each index with Group and Age as independent variable. Tukey's test was used as a post-hoc test when age

271 effects were observed.

272 Tukey's test was used as a post-hoc test when age effects were observed.

273 All analyses were run on SPSS Statistics 23 (IBM Corp, 2015), with the significance level set at $p<.05$. We computed partial eta squared $\left(\eta_{p}{ }^{2}\right)$ for effect size. According to Cohen (1988), partial eta squared of $.01, .06$ and .14 indicate small, medium and large effect sizes, respectively.

No part of the study analyses was pre-registered prior to the research being conducted.

Table 2 shows means and standard deviations on the four indices for our groups of participants.

279

Table 2. Mean z-scores on the four indices of specific functions (standard deviations shown in brackets)

\begin{tabular}{lcccccccc}
\hline & \multicolumn{3}{c}{ Schizophrenia patients } & & \multicolumn{3}{c}{ Healthy comparison participants } \\
\cline { 2 - 3 } & $\begin{array}{c}\text { Young } \\
\mathrm{n}=20\end{array}$ & $\begin{array}{c}\text { Middle } \\
\mathrm{n}=17\end{array}$ & $\begin{array}{c}\text { Older } \\
\mathrm{n}=25\end{array}$ & & $\begin{array}{c}\text { Young } \\
\mathrm{n}=20\end{array}$ & $\begin{array}{c}\text { Middle } \\
\mathrm{n}=17\end{array}$ & $\begin{array}{c}\text { Older } \\
\mathrm{n}=25\end{array}$ \\
\hline Shifting & $-.011(.641)$ & $.052(.565)$ & $-.775(.938)$ & & $.343(.460)$ & $.329(.449)$ & $.251(.359)$ \\
Updating & $.036(.893)$ & $-.337(.673)$ & $-.802(.636)$ & & $.574(.632)$ & $.461(.758)$ & $.229(.593)$ \\
Inhibition & $.403(.614)$ & $.089(.735)$ & $-.528(.931)$ & & $.382(.432)$ & $.136(.606)$ & $-.253(.573)$ \\
Access & $-.048(.873)$ & $-.460(.807)$ & $-.843(.814)$ & & $.444(.690)$ & $.571(.711)$ & $.451(.637)$ \\
\hline
\end{tabular}

\section{Results}

\footnotetext{
${ }^{2}$ For the inhibition score, we first computed a Z-score for HSCT which included time and errors before computing the inhibition score which included HSCT and SCWT, in order to give equal weight to both tests in the index. When necessary, Z-scores were recoded so that a high score reflected better performance.
} 
Table 3 presents $F$-values, $p$-values and partial eta squared for the main analyses conducted in the study.

Table 3: $F$-values, $p$-values and partial eta squared for the main analyses conducted in the study.

\begin{tabular}{lccccccccc} 
& \multicolumn{3}{c}{ Main effect of Group } & \multicolumn{3}{c}{ Main effect of Age } & \multicolumn{3}{c}{ Group * Age Interaction } \\
\cline { 2 - 10 } & \multicolumn{1}{c}{$F$} & $p$ & $\eta_{p}{ }^{2}$ & $F$ & $p$ & $\eta_{p}{ }^{2}$ & $F$ & $p$ & $\eta_{p}{ }^{2}$ \\
\hline Shifting & 24.51 & $<.001^{* * *}$ & .172 & 7.67 & $<.001^{* * *}$ & .115 & 5.00 & $.008^{* *}$ & .078 \\
Access & 46.46 & $<.001^{* * *}$ & .282 & 3.13 & $.047^{*}$ & .050 & 3.15 & $.046^{*}$ & .051 \\
Updating & 38.71 & $<.001^{* * *}$ & .247 & 8.20 & $<.001^{* * *}$ & .122 & 1.39 & .253 & .023 \\
Inhibition & .66 & .417 & .006 & 15.57 & $<.001^{* * *}$ & .209 & .59 & .553 & .010 \\
\hline
\end{tabular}

Note. ${ }^{* * *} p<.001 .{ }^{* *} p<.01 .{ }^{*} p<.05 .{ }^{+} p<.10$

Figure 1 presents means and standard errors on the four indices for our groups of participants.

\section{Schizophrenia 0 Healthy}
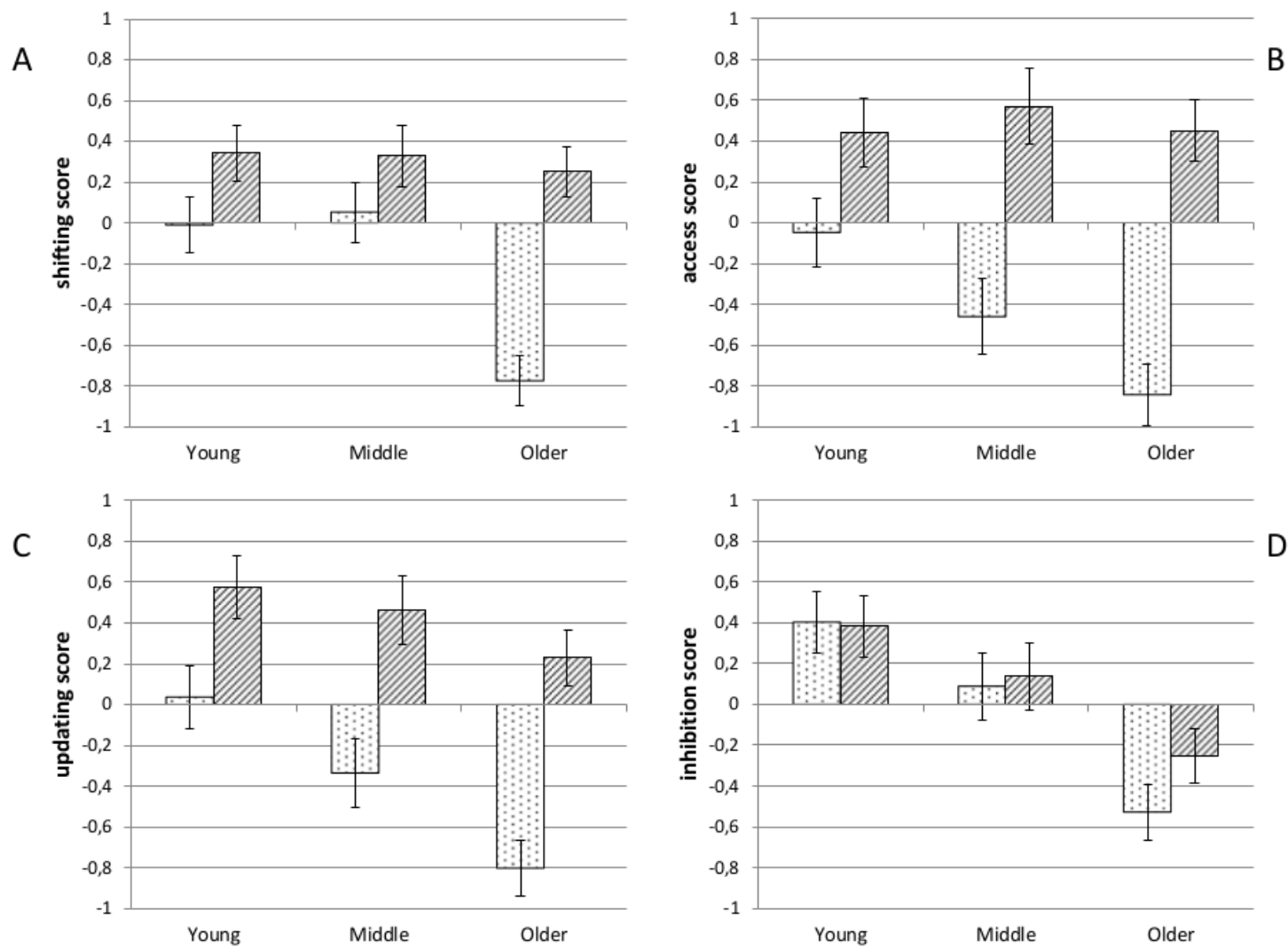
Figure 1: Z-scores for the four indices of executive functions (Panel A = Shifting, Panel B= Access, Panel $\mathrm{C}=$ Updating, Panel $\mathrm{D}=$ Inhibition) for schizophrenia patients and healthy comparison participants as a function of age group (error bars denote standard errors).

\section{Shifting tasks:}

The analysis conducted on the shifting index revealed significant effects of group $[F(1,118)=24.51$; $\left.p<.001 ; \eta_{p}{ }^{2}=.172\right]$, age $\left[F(2,118)=7.67 ; p<.001 ; \eta_{p}^{2}=.115\right]$ and age by group interaction $\left[F(2,118)=5.00 ; p=.008 ; \eta_{p}^{2}=.078\right]$. Performance was lower for patients and older participants, but the interaction revealed that the effect of age was only significant in patients $[F(2,59)=8.16$; $\left.p<.001 ; \eta_{p}{ }^{2}=.217\right]$, not in comparison participants $[F(2,59)=.31 ; p=.73]$. Moreover, post-hoc tests indicated that the difference in patients with respect to the shifting index was significant only when comparing older patients to both younger $(p=.003)$ and middle-aged patients $(p=.003)$ but not when comparing younger and middle-aged patients $(p=.966)$. Thus, these results argue strongly in favor of accelerated aging in schizophrenia patients, but only in older age.

\section{Efficiency of access to memory:}

The analysis performed on the access index revealed a significant effect of group $[F(1,118)=46.46$; $\left.p<.001 ; \eta_{p}{ }^{2}=.282\right]$, age $\left[F(2,118)=3.13 ; p=.047 ; \eta_{p}^{2}=.050\right]$ and the interaction between the two $\left[F(2,118)=3.15 ; p=.046 ; \eta_{p}{ }^{2}=.051\right]$. Performance was lower for patients than comparison participants, and the interaction revealed that the effect of age was only significant in patients $\left[F(2,59)=5.07 ; p=.009 ; \eta_{p}^{2}=.147\right]$, not in comparison participants $[F(2,59)=.21 ; p=.814]$.

Moreover, post-hoc tests showed that the difference in patients with respect to the access index was only significant when comparing older patients to younger patients $(p=.006)$, but not when comparing younger and middle-aged patients $(p=.298)$, nor aged and middle-aged patients $(p=.316)$. Even if the effect size is weak, these results therefore argue in favor of accelerated aging in schizophrenia patients as regards access to long-term memory. 
Updating tasks:

324 The analysis performed on the updating index revealed a significant effect of group $\left[F(1,118)=38.71 ; p<.001 ; \eta_{p}{ }^{2}=.247\right]$ and age $\left[F(2,118)=8.20 ; p<.001 ; \eta_{p}{ }^{2}=.122\right]$, but no interaction between the two $[F(2,118)=1.39 ; p=.253]$. Post-hoc tests in respect of the effect of age yielded a significant difference between older and younger participants $(p<.001)$ but only a marginal difference between older and middle-aged participants $(p=.067)$ and no difference between younger and middle-aged participants $(p=.296)$. In updating tasks, patients' performance participants. However, the effect of age was no more deleterious in patients than in comparison participants.

Inhibition tasks:

The analysis conducted on the inhibition index showed an effect of age $[F(2,118)=15.57 ; p<.001$; $\left.\eta_{p}{ }^{2}=.209\right]$, but no effect of group $[F(1,118)=.66 ; p=.417]$, nor interaction $[F(2,118)=.59$; $p=.553]$. Post-hoc tests showed that the effect of age was significant when comparing older patients to both younger $(p<.001)$ and middle-aged patients $(p=.003)$ but not when comparing younger and middle-aged patients $(p=.183)$. Thus, inhibition abilities decrease in older participants, but in the case of this measure schizophrenia patients were not impaired compared to healthy comparisons participants.

\section{Discussion}

The aim of this study was to determine whether a particular specific executive function could be a sensitive indicator of accelerated aging in schizophrenia. The main result is that accelerated aging does not affect all of the four specific executive functions. According to the literature about normal 
aging, shifting, updating and inhibition show age-related decline whereas access is preserved. In our sample, schizophrenia patients show the same cognitive deterioration as healthy comparison participants with regard to updating and inhibition. Thus, concerning these specific functions, schizophrenia patients appear normally affected by age. However, shifting and access were impaired in older schizophrenia patients, whereas in healthy comparison participants these functions were not affected by age, suggesting that age has a pathological effect on shifting and access in schizophrenia. The function most affected by age in schizophrenia is the shifting ability. Our results suggest that this function is not affected by age in middle-aged patients but is severely impaired in elderly patients. Access to long-term memory also showed accelerated aging. Even if the effect size is weaker than for shifting, suggesting this result needs replication, it seems important to note that the change with age is different. Contrary to shifting, which showed a decline only for older patients, the difference with respect to access was only significant between younger and older patients, suggesting an early accelerated age decline of access, and a late accelerated decline of shifting in patients. It should be noted that processing speed contributes to both shifting and access tasks (Fisk \& Sharp, 2004; Neill \& Rossell, 2013), and so it is possible processing speed may be the underlying factor explaining the accelerated aging in schizophrenia. Although processing speed is particularly involved in verbal fluency tests (Nuechterlein et al., 2008), the shift cost index used in the present study for shifting tasks should have reduce the influence of processing speed. Moreover, since processing speed is also involved in updating and inhibition, these functions should also show accelerated aging, which is not the case here. Thus, although processing speed contributes to executive performance, the present data lend greater weight to the idea that processing speed is not the main underlying factor explaining accelerated aging in schizophrenia. Further research is required to separate the contribution of processing speed more from executive performance in schizophrenia aging. Lastly, executive functions degradation in schizophrenia patients may accelerate before age of 65 against what was suggested for global cognition (J. I. Friedman et al., 
2001; Rajji \& Mulsant, 2008). These results are of great interest for both research and clinical practice.

From a research perspective, the present results emphasize the need to consider the diversity of executive functions when studying cognition in schizophrenia, especially when looking for links between executive functions and other variables (such as medication or outcome). In fact, these relationships may be specifically linked to some functions but not to others and the use of general tests may lead to inaccurate conclusions. It seems that shifting and access abilities decline more rapidly in schizophrenia than in healthy comparison participants. This may explain, at least in part, the controversial results reported in the literature about schizophrenia aging in executive functions, insofar as with general executive tests it may be possible to observe impaired or preserved executive functioning in schizophrenia although some deficits may exist but are restricted to one or two domains. For instance, using only the Wisconsin Card Sorting Test, which is known to be strongly linked to shifting (Miyake et al., 2000), may produce a conclusion of accelerated aging in respect of executive functioning in schizophrenia (Fucetola et al., 2000), whereas it may hide some disparities among executive functions.

Moreover, the fact that, contrary to many studies (Laurenson et al., 2015; Westerhausen et al., 2011), we failed to observe an effect of the schizophrenia pathology on the inhibition index may reflect the considerable heterogeneity in schizophrenia patients. More specifically, previous studies using the HSCT also failed to report any difference between patients and healthy comparison participants (Chan et al., 2010; Laurenson et al., 2015), and data on the SCWT are controversial (Westerhausen et al., 2011). Another hypothesis to be taken into account is the interference index used in the SCWT (Perlstein, Carter, Barch, \& Baird, 1998), given that an analysis conducted using the classical index indicated that schizophrenia patients showed less interference than comparison participants, whereas another interference index (more similar to the one we used) showed no group difference. As proposed by $\mathrm{Li}$ and Bosman (Li \& Bosman, 1996), we therefore suggest that when assessing 
SCWT in participants who may reflect cognitive slowing, such as older participants or psychiatric patients, it would be more thorough to use an index that takes account of these participants' higher baseline latency. A previous study (Donohoe et al., 2006) also indicated that inhibition is the only specific executive function that correlated with symptom severity, the suggestion being that inhibition in schizophrenia may be a very complex field showing high inter-individual heterogeneity. Thus, inhibition is probably not spared in schizophrenia but may be influenced by several possible confounders which can reduce statistical power.

According to previous researches showing that schizophrenia is a neurodevelopmental pathology (Meier et al., 2014; Sheffield et al., 2018), it is possible that white and grey matter deteriorations observed in schizophrenia patients (Orellana \& Slachevsky, 2013; Zierhut et al., 2013) act as a vulnerability factor during late adulthood. The prefrontal cortex and its connections, which are already reduced in patients, would be even more affected by aging. More specifically, further researches may look at the effect of aging on the cingulate cortex and its connections with the prefrontal cortex in older schizophrenia patients. Indeed, abnormal connectivity has been observed between thalamus, anterior cingulate and dorsolateral prefrontal cortex in schizophrenia (Wagner et al., 2015), and the cingulate cortex is implicated in both shifting (Wilmsmeier et al., 2010) and access (Tyburski, Sokołowski, Cheć, Pełka-Wysiecka, \& Samochowiec, 2015) tasks as well as in networks showing exaggerated vulnerability to aging in schizophrenia (Sheffield et al., 2016). Thus, evidence about accelerated aging in these regions would provide anatomic support about the accelerated aging in shifting and access tasks in schizophrenia.

417 As schizophrenia patients' longevity increases and because higher cognitive deficits increase the risk of dementia (Van Assche, Morrens, Luyten, Van de Ven, \& Vandenbulcke, 2017), it is important to adapt remediation programs to the specificity of older patients. Improving cognition in these patients may have several benefits such as higher quality of life, autonomy and perhaps 421 preventing from dementia. A program dedicated specifically to these patients should teach 
compensatory strategies and develop exercises that deal with shifting, which are efficient in schizophrenia patients (Wykes et al., 2007), although some modifications are needed for it to be effective for older patients (Wykes et al., 2009). Concerning access, patients could be taught searching strategies (Martin, Wiggs, Lalonde, \& Mack, 1994) and organizational strategies (Scheuringer, Wittig, \& Pletzer, 2017) as a way of helping them to improve their memory. In this way, metacognitive approaches may be of interest, as monitoring skills training (Dunlosky, KubatSilman, \& Hertzog, 2003) and memory strategies teaching (Troyer, 2001) has proved effective in healthy older participants. Moreover, a combination of these two components in a remediation program could yield unexpected results as shifting is closely associated with clustering in memory (Taconnat et al., 2009) and metamemory accuracy (Perrotin, Tournelle, \& Isingrini, 2008).

Nevertheless, the inclusion of schizophrenia patients in remediation programs should account of our own results and those of previous studies (Rabanea-Souza et al., 2016; Raffard \& Bayard, 2012; Wongupparaj et al., 2015) which argue for the assessment of specific executive functions as a complement to classical tests before a patient is admitted on a remediation program. Thus, given the considerable heterogeneity of patients' cognitive profiles (Raffard \& Bayard, 2012), this would allow for better targeting of specific deficits as well as time-savings for patients who do not need to work on certain abilities.

This research has several strengths and limitations. First of all, to the best of our knowledge this is the first time the executive profile of older schizophrenia patients has been assessed with a validated model of executive functioning (Fisk \& Sharp, 2004; Miyake et al., 2000). This method produces more accurate results concerning the cognitive deficit in schizophrenia and its course in later life. Moreover, only a few studies used strict pairing in respect of gender, age and education between patients and comparison participants despite the well-known effects of these variables on cognition and methodological recommendations (Fioravanti et al., 2012). Specifically, in the case of studies on aging, such demographic variables may interact as older participants often have fewer years of 
education, there were more differences in women's education 60 years ago compared to now, and schizophrenia patients leave school earlier. Thus, thanks to the strict pairing in our study, effect sizes are often large even if our sample is relatively small. We were not able to control former patients' medication and to clarify the long-term effects of medication on cognitive functioning, which may be a recurrent problem in studies on schizophrenia aging (Suzuki, Gen, \& Inoue, 2011). More precisely, second-generation antipsychotics have more beneficial effects on cognition than first-generation ones (Désaméricq et al., 2014; Guilera, Pino, Gómez-Benito, \& Rojo, 2009; Keefe, Silva, Perkins, \& Lieberman, 1999; Woodward, Purdon, Meltzer, \& Zald, 2005), and older schizophrenia patients, unlike younger ones, may have been treated with first-generation antipsychotics for several years before the discovery of new treatments. Moreover, first-generation antipsychotics are often more prevalent in current treatment of older schizophrenia patients than in young patients. However, schizophrenia patients were treated in accordance with the guidelines for biological treatment of schizophrenia published by the World Federation of Societies of Biological Psychiatry (Hasan et al., 2012, 2013). They received stable doses for at least four weeks at inclusion and throughout the duration of the study, and most of the patients were administered only one antipsychotic which would presumably not result in excessive cognitive dysfunction. Schizophrenia patients also show a higher prevalence of tobacco smoking, and recent research shows that the longterm effects of tobacco smoking are deleterious on processing speed in patients (Vermeulen et al., 2018). Unfortunately, these results were not known by our team when the project started, and so these data were not taken into account. As processing speed influences other cognitive functions, 467 especially the effect of aging on shifting abilities (Salthouse, Fristoe, McGuthry, \& Hambrick, 1998), it is still possible that a long history of tobacco smoking in elderly patients partially influenced our results. The effect of past and current work status may also influence cognition (Ansiau, Marquié, Soubelet, \& Ramos, 2005; Wilson et al., 2003), especially in a detrimental way

471 for elderly participants who may have retired. However, taking this problem into account properly 
472 (intellectual demands of the job, number of years worked, how long ago the participant stopped 473 working, etc.) would be complex and should be investigated in future research. More specifically,

474

475 such research should incorporate a measure including a large number of factors, such as the intellectual and physical demands of the job, modulated according to the number of years worked. Another potential criticism to this study is that comparison participants did not show age related effects on two specific executive functions. Although it seems normal for access which should not be affected by age (Fisk \& Sharp, 2004), it is more uncommon for shifting. Even if some studies didn't find age effect on plus-minus task (Etienne, Marin-Lamellet, \& Laurent, 2008) or numberletter task (Delaloye et al., 2009), we acknowledge that our participants were not as old as typically found in normal aging studies. This may explain the failure to show age-related effects on shifting in comparison participants despite a decrease in healthy older participants' performance. However, schizophrenia patients have higher mortality rates than general population (Lee et al., 2018) so that recruiting patients older than 70 would be very difficult and not representative of this population. We therefore chose age groups according to the literature on schizophrenia (Fucetola et al., 2000) and to keep strict pairing for comparison participants. The term "accelerated aging" may therefore appear inappropriate as healthy participants did not show age effects on these functions. However age-related effects on shifting are well documented (Clarys et al., 2009; Fisk \& Sharp, 2004; Schnitzspahn et al., 2013) which is not the case for access (Fisk \& Sharp, 2004). Thus, the term "pathologic aging" might be more appropriate for age-related effects on access in schizophrenia. Finally, as Anxiety and Depressions scores did not correlate with all of the specific executive functions, we decided not to include these scores in the analyses to make them easier to understand. However, we conducted the same analyses with entering Anxiety and Depression as covariates to find out whether these variables may alter the results. This was the case only for the interaction between Schizophrenia and Age on Access index which turned marginal (from $p=.046$ to $p=.051$ ) when the depression score was entered as a covariate. While we acknowledge that depression scores 
may contribute to the interaction between Schizophrenia and Age on Access, the difference between the two p-values is relatively small. Moreover, since higher depression scores are common in schizophrenia patients, controlling for these symptoms may hide part of the pathology.

\section{Conclusions}

This study emphasizes the importance of considering the diversity of executive functions in schizophrenia. In this way, our results indicate that shifting shows early accelerated aging and access to long-term memory shows late pathologic decline, whereas updating and inhibition did not show accelerated aging. Thus, specific executive functions should be evaluated before admitting patients on remediation programs, which ought to be adapted to older patients.

\section{Declarations of interest: None.}

Author contributions: Flavien Thuaire: Conceptualization, Data curation, Formal analysis, Investigation, Methodology, Writing - original draft, Writing - review \& editing. Fabien Rondepierre: Data curation, Resources, Visualization, Writing - review \& editing. Elisabeth Bacon: Resources, Supervision. Guillaume T. Vallet: Formal analysis, Writing - review \& editing. Isabelle Jalenques: Resources, Supervision, Writing - review \& editing. Marie Izaute: Methodology, Project administration, Supervision, Validation, Writing - review \& editing.

Acknowledgments: This work was supported by the CNRS, INSERM, the UCA of ClermontFerrand, and Clermont-Ferrand University Hospital. The authors would like to thank Gillian Wakenhut for her accuracy and patience with correcting our English and two anonymous reviewers for their helpful comments on this article. 
523 Funding: This work was supported by the European Union and the Auvergne-Rhône-Alpes region 524 [Grant number AV0017611].

525

526

527

528

529

530

531

532

533

534

535

536

537

538

539

540

541

542

543

544

545

546

547

548

549

550

551

552

553

\section{References:}

Abelson, R. P., \& Prentice, D. A. (1997). Contrast tests of interaction hypothesis. Psychological Methods, 2(4), 315-328. https://doi.org/10.1037/1082-989X.2.4.315

Adrover-Roig, D., Sesé, A., Barceló, F., \& Palmer, A. (2012). A latent variable approach to executive control in healthy ageing. Brain and Cognition, 78(3), 284-299. https://doi.org/10.1016/j.bandc.2012.01.005

Andrés, P., \& Van der Linden, M. (2000). Age-Related Differences in Supervisory Attentional System Functions. The Journals of Gerontology Series B, 55(6), 373-380. https://doi.org/10.1093/geronb/55.6.P373

Ansiau, D., Marquié, J. C., Soubelet, A., \& Ramos, S. (2005). Relationships between cognitive characteristics of the job, age, and cognitive efficiency. International Congress Series, 1280, 43-48. https://doi.org/10.1016/j.ics.2005.01.020

Azur, M. J., Stuart, E. A., Frangakis, C., \& Leaf, P. J. (2011). Multiple Imputation by Chained Equations: What is it and how does it work? International Journal of Methods in Psychiatric Research, 20(1), 40-49. https://doi.org/10.1002/mpr.329.Multiple

Bowie, C. R., Reichenberg, A., McClure, M. M., Leung, W. L., \& Harvey, P. D. (2008). Ageassociated differences in cognitive performance in older community dwelling schizophrenia patients: Differential sensitivity of clinical neuropsychological and experimental information processing tests. Schizophrenia Research, 106(1), 50-58. https://doi.org/10.1016/j.schres.2007.10.026

Bryan, J., Luszcz, M. A., \& Pointer, S. (1999). Executive Function and Processing Resources as Predictors of Adult Age Differences in the Implementation of Encoding Strategies. Aging, Neuropsychology, and Cognition, 6(4), 273-287. https://doi.org/10.1076/13825585(199912)06

Burgess, P. W., \& Shallice, T. (1996). Response suppression, Initiation and strategy use following 
frontal lobe lesions. Neuropsychologia, 34(4), 263-272. https://doi.org/10.1016/00283932(95)00104-2

Ceaser, A. E., Goldberg, T. E., Egan, M. F., McMahon, R. P., Weinberger, D. R., \& Gold, J. M. (2008). Set-Shifting Ability and Schizophrenia: A Marker of Clinical Illness or an Intermediate Phenotype? Biological Psychiatry, 64(9), 782-788. https://doi.org/10.1016/j.biopsych.2008.05.009

Chan, R. C. K., Chen, E. Y. H., \& Law, C. W. (2006). Specific executive dysfunction in patients with first-episode medication-naïve schizophrenia. Schizophrenia Research, 82(1), 51-64. https://doi.org/10.1016/j.schres.2005.09.020

Chan, R. C. K., Huang, J., Guo, L., Cao, X., Hong, X., \& Gao, Z. (2010). Executive control in schizophrenia in task involving semantic inhibition and working memory. Psychiatry Research, 179(3), 259-266. https://doi.org/10.1016/j.psychres.2009.07.014

Chen, T., Xu, M., Tu, J., Wang, H., \& Niu, X. (2018). Relationship between Omnibus and Posthoc Tests: An Investigation of performance of the F test in ANOVA. Shanghai Archives of Psychiatry, 30(1), 60-64. https://doi.org/10.11919/j.issn.1002-0829.218014

Clarys, D., Bugaiska, A., Tapia, G., \& Baudouin, A. (2009). Ageing, remembering, and executive function. Memory, 17(2), 158-168. https://doi.org/10.1080/09658210802188301

Cohen, C., Vahia, I., Reyes, P., Diwan, S., Bankole, A., Palekar, N., ... Ramirez, P. (2008). Schizophrenia in Later Life : Clinical Symptoms and Social Well-being. Psychiatric Services, 59(3), 232-234. https://doi.org/10.1176/ps.2008.59.3.232

Cohen, J. (1988). Statistical power Analysis for the Behavioral Sciences (2nd ed). New York: NY Academic Press.

Cona, G., Arcara, G., Amodio, P., Schiff, S., \& Bisiacchi, P. S. (2013). Does executive control really play a crucial role in explaining age-related cognitive and neural differences. Neuropsychology, 27(3), 378-389. https://doi.org/10.1037/a0032708

Culbreth, A., Westbrook, A., \& Barch, D. (2016). Negative Symptoms are Associated with an Increased Subjective Cost of Cognitive Effort. Journal of Abnormal Psychology, 125(4), 528-536. https://doi.org/10.1037/abn0000153.Negative

Delaloye, C., Moy, G., Baudois, S., De Bilbao, F., Dubois Remund, C., Hofer, F., ... Giannakopoulos, P. (2009). The contribution of aging to the understanding of the dimensionality of executive functions. Archives of Gerontology and Geriatrics, 49(1), 51-59. https://doi.org/10.1016/j.archger.2008.08.011

Désaméricq, G., Schurhoff, F., Meary, A., Szöke, A., Macquin-Mavier, I., Bachoud-Lévi, A. C., \& Maison, P. (2014). Long-term neurocognitive effects of antipsychotics in schizophrenia: A 
network meta-analysis. European Journal of Clinical Pharmacology, 70(2), 127-134. https://doi.org/10.1007/s00228-013-1600-y

Donohoe, G., Corvin, A., \& Robertson, I. H. (2006). Evidence that specific executive functions predict symptom variance among schizophrenia patients with a predominantly negative symptom profile. Cognitive Neuropsychiatry, 11(1), 13-32. https://doi.org/10.1080/13546800444000155

Dunlosky, J., Kubat-Silman, A. K., \& Hertzog, C. (2003). Training monitoring skills improves older adults' self-paced associative learning. Psychology and Aging, 18(2), 340-345. https://doi.org/10.1037/0882-7974.18.2.340

Etienne, V., Marin-Lamellet, C., \& Laurent, B. (2008). Évolution Du Contrôle Exécutif Au Cours Du Vieillissement Normal. Revue Neurologique, 164(12), 1010-1017. https://doi.org/10.1016/j.neurol.2008.03.021

Evans, J. D., Heaton, R. K., Paulsen, J. S., Palmer, B. W., Patterson, T., \& Jeste, D. V. (2003). The relationship of neuropsychological abilities to specific domains of functional capacity in older schizophrenia patients. Biological Psychiatry, 53(5), 422-430. https://doi.org/10.1016/S0006-3223(02)01476-2

Facchin, A., Sartori, E., Luisetti, C., De Galeazzi, A., \& Beschin, N. (2019). Effect of prism adaptation on neglect hemianesthesia. Cortex, 113, 298-311. https://doi.org/10.1016/j.cortex.2018.12.021

Fioravanti, M., Bianchi, V., \& Cinti, M. E. (2012). Cognitive deficits in schizophrenia: an updated metanalysis of the scientific evidence. BMC Psychiatry, 12(64), 1471-244. https://doi.org/10.1186/1471-244X-12-64

Fisk, J. E., \& Sharp, C. A. (2004). Age-related impairment in executive functioning: Updating, inhibition, shifting, and access. Journal of Clinical and Experimental Neuropsychology, 26(7), 874-890. https://doi.org/10.1080/13803390490510680

Friedman, J. I., Harvey, P. D., Coleman, T., Moriarty, P. J., Bowie, C., Parrella, M., ... Davis, K. L. (2001). Six-Year Follow-Up Study of Cognitive and Functional Status Across the Lifespan in Schizophrenia: A Comparison With Alzheimer's Disease and Normal Aging. American Journal of Psychiatry, 158(9), 1441-1448. https://doi.org/10.1176/appi.ajp.158.9.1441

Friedman, N. P., \& Miyake, A. (2017). Unity and Diversity of Executive Functions: Individual Differences as a Window on Cognitive Structure. Cortex, 86, 186-204. https://doi.org/10.1016/j.cogdev.2010.08.003.Personal

Fucetola, R., Seidman, L. J., Kremen, W. S., Faraone, S. V., Goldstein, J. M., \& Tsuang, M. T. (2000). Age and neuropsychologic function in schizophrenia: A decline in executive abilities 
beyond that observed in healthy volunteers. Biological Psychiatry, 48(2), 137-146. https://doi.org/10.1016/S0006-3223(00)00240-7

Green, M. F. (2016). Impact of cognitive and social cognitive impairment on functional outcomes in patients with schizophrenia. The Journal of Clinical Psychiatry, 77 Suppl 2(April 2013), 8-11. https://doi.org/10.4088/JCP.14074su1c.02

Guilera, G., Pino, O., Gómez-Benito, J., \& Rojo, J. E. (2009). Antipsychotic effects on cognition in schizophrenia: A meta-analysis of randomised controlled trials. European Journal of Psychiatry, 23(2), 77-89. https://doi.org/10.4321/S0213-61632009000200002

Harvey, P. D., Parrella, M., White, L., Mohs, R. C., \& Davis, K. L. (1999). Convergence of cognitive and functional decline in poor outcome schizophrenia. Schizophrenia Research, 35, $77-84$.

Harvey, P. D., \& Rosenthal, J. B. (2018). Cognitive and functional deficits in people with schizophrenia: Evidence for accelerated or exaggerated aging? Schizophrenia Research, 196, 14-21. https://doi.org/10.1016/j.schres.2017.05.009

Hasan, A., Falkai, P., Wobrock, T., Lieberman, J., Glenthoj, B., Gattaz, W. F., .. Möller, H. J. (2012). World Federation of Societies of Biological Psychiatry (WFSBP) Guidelines for Biological Treatment of Schizophrenia, Part 1: Update 2012 on the acute treatment of schizophrenia and the management of treatment resistance. World Journal of Biological Psychiatry, 13(5), 318-378. https://doi.org/10.3109/15622975.2012.696143

Hasan, A., Falkai, P., Wobrock, T., Lieberman, J., Glenthoj, B., Gattaz, W. F., ... Möller, H. J. (2013). World Federation of Societies of Biological Psychiatry (WFSBP) Guidelines for Biological Treatment of Schizophrenia, Part 2: Update 2012 on the long-term treatment of schizophrenia and management of antipsychotic-induced side effects. World Journal of Biological Psychiatry, 14(1), 2-44. https://doi.org/10.3109/15622975.2012.739708

Heinrichs, R. W., \& Zakzanis, K. K. (1998). Neurocognitive deficit in schizophrenia: a quantitative review of the evidence. Neuropsychology, 12(3), 426-445. https://doi.org/10.1037/0894-4105.12.3.426

Herold, C. J., Schmid, L. A., Lässer, M. M., Seidl, U., \& Schröder, J. (2017). Cognitive Performance in Patients with Chronic Schizophrenia Across the Lifespan. GeroPsych, 30(1), 35-44. https://doi.org/10.1024/1662-9647/a000164

IBM Corp. (2015). IBM SPSS Statistics for Windows, Version 23.0. Armonk: IBM Corp. Irani, F., Brensinger, C., Richard, J., Calkins, M. E., Moberg, P. J., Bilker, W., ... Gur, R. C. (2012). Computerized Neurocognitive Test Performance in Schizophrenia: A Lifespan Analysis. American Journal of Geriatric Psychiatry, 20(1), 41-52. 

https://doi.org/10.1109/TMI.2012.2196707.Separate

Irani, F., Kalkstein, S., Moberg, E. A., \& Moberg, P. J. (2011). Neuropsychological performance in older patients with schizophrenia: A meta-analysis of cross-sectional and longitudinal studies. Schizophrenia Bulletin, 37(6), 1318-1326. https://doi.org/10.1093/schbul/sbq057

Jersild, A. T. (1927). Mental set and shift. Archives of Psychology, 14(Whole No 89).

Jeste, D. V., Wolkowitz, O. M., \& Palmer, B. W. (2011). Divergent trajectories of physical, cognitive, and psychosocial aging in schizophrenia. Schizophrenia Bulletin, 37(3), 451-455. https://doi.org/10.1093/schbul/sbr026

Jurado, M. B., \& Rosselli, M. (2007). The elusive nature of executive functions: A review of our current understanding. Neuropsychology Review, 17(3), 213-233. https://doi.org/10.1007/s11065-007-9040-z

Kalache, S. M., Mulsant, B. H., Davies, S. J. C., Liu, A. Y., Voineskos, A. N., Butters, M. A., ... Rajji, T. K. (2015). The Impact of Aging, Cognition, and Symptoms on Functional Competence in Individuals with Schizophrenia Across the Lifespan. Schizophrenia Bulletin, 41(2), 374-381. https://doi.org/10.1093/schbul/sbu114

Kay, S. R., Fiszbein, A., \& Opler, L. A. (1987). The Positive and Negative Syndrome Scale (PANSS) for Schizophrenia. Schizophrenia Bulletin, 13(2), 261-276. https://doi.org/10.1093/schbul/13.2.261

Keefe, R. S. E., Silva, S. G., Perkins, D. O., \& Lieberman, J. A. (1999). The effects of atypical antipsychotic drugs on neurocognitive impairment in schizophrenia: A review and metaanalysis. Schizophrenia Bulletin, 25(2), 201-222. https://doi.org/10.1093/oxfordjournals.schbul.a033374

Kerns, J. G., Nuechterlein, K. H., Braver, T. S., \& Barch, D. M. (2008). Executive Functioning Component Mechanisms and Schizophrenia. Biological Psychiatry, 64(1), 26-33. https://doi.org/10.1016/j.biopsych.2008.04.027

Knapp, F., Viechtbauer, W., Leonhart, R., Nitschke, K., \& Kaller, C. P. (2017). Planning performance in schizophrenia patients: A meta-analysis of the influence of task difficulty and clinical and sociodemographic variables. Psychological Medicine, 47(11), 1-15. https://doi.org/10.1017/S0033291717000459

Laurenson, C., Gorwood, P., Orsat, M., Lhuillier, J. P., Le Gall, D., \& Richard-Devantoy, S. (2015). Cognitive control and schizophrenia: The greatest reliability of the Stroop task. Psychiatry Research, 227(1), 10-16. https://doi.org/10.1016/j.psychres.2015.03.004

Lee, E. E., Liu, J., Tu, X., Palmer, B. W., Eyler, L. T., \& Jeste, D. V. (2018). A widening longevity gap between people with schizophrenia and general population: A literature review 
and call for action. Schizophrenia Research, 196, 9-13.

https://doi.org/10.1016/j.schres.2017.09.005

Li, K. Z. H., \& Bosman, E. A. (1996). Age Differences in Stroop-Like Interference as a Function of Semantic Relatedness. Aging, Neuropsychology, and Cognition, 3(4), 272-284.

Loewenstein, D. A., Czaja, S. J., Bowie, C. R., \& Harvey, P. D. (2012). Age-associated differences in cognitive performance in older patients with schizophrenia: A comparison with healthy older adults. American Journal of Geriatric Psychiatry, 20(1), 29-40. https://doi.org/10.1097/JGP.0b013e31823bc08c

Logan, G. D. (1985). Executive control of thought and action. Acta Psychologica, 60, 193-210. Luria, A. R. (1966). Higher Cortical Functions in Man. New York: Basic Book.

Martin, A., Wiggs, C. L., Lalonde, F., \& Mack, C. (1994). Word retrieval to letter and semantic cues: A double dissociation in normal subjects using interference tasks. Neuropsychologia, 32(12), 1487-1494. https://doi.org/10.1016/0028-3932(94)90120-1

McClure, M. M., Bowie, C. R., Patterson, T. L., Heaton, R. K., Weaver, C., Anderson, H., \& Harvey, P. D. (2007). Correlations of functional capacity and neuropsychological performance in older patients with schizophrenia: Evidence for specificity of relationships? Schizophrenia Research, 89(1-3), 330-338. https://doi.org/10.1016/j.schres.2006.07.024

Meier, M. H., Caspi, A., Reichenberg, A., Keefe, R. S. E., Fisher, H. L., Harrington, H., ... Moffitt, T. E. (2014). Neuropsychological decline in schizophrenia from the premorbid to the postonset period: Evidence from a population-representative longitudinal study. American Journal of Psychiatry, 171(1), 91-101. https://doi.org/10.1176/appi.ajp.2013.12111438

Mesholam-Gately, R. I., Giuliano, A. J., Goff, K. P., Faraone, S. V., \& Seidman, L. J. (2009). Neurocognition in First-Episode Schizophrenia: A Meta-Analytic Review. Neuropsychology, 23(3), 315-336. https://doi.org/10.1037/a0014708

Minzenberg, M., Laird, A., Thelen, S., Carter, C. S., \& Glahn, D. C. (2009). Meta-analysis of 41 functional neuroimaging studies of executive function in schizophrenia. Archives of General ..., 66(8), 811-822. https://doi.org/10.1001/archgenpsychiatry.2009.91.Meta-analysis

Miyake, A., Friedman, N. P., Emerson, M. J., Witzki, A. H., Howerter, A., \& Wager, T. D. (2000). The Unity and Diversity of Executive Functions and Their Contributions to Complex "Frontal Lobe" Tasks: A Latent Variable Analysis. Cognitive Psychology, 41(1), 49-100. https://doi.org/10.1006/cogp.1999.0734

Mohamed, S., Rosenheck, R., Swartz, M., Stroup, S., Lieberman, J. A., \& Keefe, R. S. E. (2008). Relationship of cognition and psychopathology to functional impairment in schizophrenia. American Journal of Psychiatry, 165(8), 978-987. 

https://doi.org/10.1176/appi.ajp.2008.07111713

Nathaniel-James, D. A., Brown, R., \& Ron, M. A. (1996). Memory impairment in schizophrenia: Its' relationship to executive function. Schizophrenia Research, 21(2), 85-96. https://doi.org/10.1016/0920-9964(96)00038-2

Neill, E., \& Rossell, S. L. (2013). Executive functioning in schizophrenia: The result of impairments in lower order cognitive skills? Schizophrenia Research, 150(1), 76-80. https://doi.org/10.1016/j.schres.2013.07.034

Nuechterlein, K. H., Green, M. F., Kern, R. S., Baade, L. E., Barch, D. M., Cohen, J. D., ... Marder, S. R. (2008). The MATRICS consensus cognitive battery, part 1: Test selection, reliability, and validity. American Journal of Psychiatry, 165(2), 203-213. https://doi.org/10.1176/appi.ajp.2007.07010042

Orellana, G., \& Slachevsky, A. (2013). Executive functioning in schizophrenia. Frontiers in Psychiatry, 4(JUN), 1-15. https://doi.org/10.3389/fpsyt.2013.00035

Perlstein, W. M., Carter, C. S., Barch, D. M., \& Baird, J. W. (1998). The Stroop task and attention deficits in schizophrenia: A critical evaluation of card and single-trial Stroop methodologies. Neuropsychology, 12(3), 414-425. https://doi.org/10.1037/0894-4105.12.3.414

Perrotin, A., Belleville, S., \& Isingrini, M. (2007). Metamemory monitoring in mild cognitive impairment: Evidence of a less accurate episodic feeling-of-knowing. Neuropsychologia, 45(12), 2811-2826. https://doi.org/10.1016/j.neuropsychologia.2007.05.003

Perrotin, A., Tournelle, L., \& Isingrini, M. (2008). Executive functioning and memory as potential mediators of the episodic feeling-of-knowing accuracy. Brain and Cognition, 67(1), 76-87. https://doi.org/10.1016/j.bandc.2007.11.006

Petrides, M., \& Milner, B. (1982). Deficits on subject-ordered tasks after frontal- and temporallobe lesions in man. Neuropsychologia, 20(3), 249-262.

Piolino, P., Coste, C., Martinelli, P., Macé, A. L., Quinette, P., Guillery-Girard, B., \& Belleville, S. (2010). Reduced specificity of autobiographical memory and aging: Do the executive and feature binding functions of working memory have a role? Neuropsychologia, 48(2), 429440. https://doi.org/10.1016/j.neuropsychologia.2009.09.035

Rabanea-Souza, T., Akiba, H. T., Berberian, A. A., Bressan, R. A., Dias, Á. M., \& Lacerda, A. L. T. (2016). Neuropsychological correlates of remission in chronic schizophrenia subjects: The role of general and task-specific executive processes. Schizophrenia Research: Cognition, 3, 39-46. https://doi.org/10.1016/j.scog.2015.12.001

Raffard, S., \& Bayard, S. (2012). Understanding the executive functioning heterogeneity in schizophrenia. Brain and Cognition, 79(1), 60-69. 
https://doi.org/10.1016/j.bandc.2012.01.008

Rajji, T. K., \& Mulsant, B. H. (2008). Nature and course of cognitive function in late-life schizophrenia: A systematic review. Schizophrenia Research, 102, 122-140. https://doi.org/10.1016/j.schres.2008.03.015

Reichenberg, A., \& Harvey, P. D. (2007). Neuropsychological impairments in schizophrenia: Integration of performance-based and brain imaging findings. Psychological Bulletin, 133(5), 833-858. https://doi.org/10.1037/0033-2909.134.3.382

Rogers, R. D., \& Monsell, S. (1995). Costs of a Predictable Switch Between Simple Cognitive Tasks. Journal of Experimental Psychology: General, 124(2), 207-231. https://doi.org/10.1037/0894-4105.20.6.675

Rossell, S. L. (2006). Category fluency performance in patients with schizophrenia and bipolar disorder: The influence of affective categories. Schizophrenia Research, 82, 135-138. https://doi.org/10.1016/j.schres.2005.10.013

Salthouse, T. A., Atkinson, T. M., \& Berish, D. E. (2003). Executive Functioning as a Potential Mediator of Age-Related Cognitive Decline in Normal Adults. Journal of Experimental Psychology: General, 132(4), 566-594. https://doi.org/10.1037/0096-3445.132.4.566

Salthouse, T. A., Fristoe, N., McGuthry, K. E., \& Hambrick, D. Z. (1998). Relation of task switching to speed, age, and fluid intelligence. Psychology and Aging, 13(3), 445-461. https://doi.org/10.1037/0882-7974.13.3.445

Scheuringer, A., Wittig, R., \& Pletzer, B. (2017). Sex differences in verbal fluency: the role of strategies and instructions. Cognitive Processing, 18(4), 407-417. https://doi.org/10.1007/s10339-017-0801-1

Schnack, H. G., Van Haren, N. E. M., Nieuwenhuis, M., Pol, H. E. H., Cahn, W., \& Kahn, R. S. (2016). Accelerated brain aging in schizophrenia: A longitudinal pattern recognition study. American Journal of Psychiatry, 173(6), 607-616. https://doi.org/10.1176/appi.ajp.2015.15070922

Schnitzspahn, K. M., Stahl, C., Zeintl, M., Kaller, C. P., \& Kliegel, M. (2013). The role of shifting, updating, and inhibition in prospective memory performance in young and older adults. Developmental Psychology, 49(8), 1544-1553. https://doi.org/10.1037/a0030579

Shallice, T. (1982). Specific Impairments of Planning. Philosophical Transactions of the Royal Society of London, 209, 199-209. https://doi.org/10.1098/rstb.1982.0082

Sheffield, J. M., Karcher, N. R., \& Barch, D. M. (2018). Cognitive Deficits in Psychotic Disorders: A Lifespan Perspective. Neuropsychology Review. https://doi.org/10.1007/s11065018-9388-2 
Sheffield, J. M., Repovs, G., Harms, M. P., Carter, C. S., Gold, J. M., Macdonald, A. W., ... Barch, D. M. (2016). Evidence for accelerated decline of functional brain network efficiency in schizophrenia. Schizophrenia Bulletin, 42(3), 753-761. https://doi.org/10.1093/schbul/sbv148

Silver, H., Goodman, C., Gur, R. C., Gur, R. E., \& Bilker, W. B. (2011). "Executive” functions and normal aging: Selective impairment in conditional exclusion compared to abstraction and inhibition. Dementia and Geriatric Cognitive Disorders, 31(1), 53-62. https://doi.org/10.1159/000322568

Silverstein, A. B. (1982). Two-and Four-Subtest Short Forms of the Wechsler Adult Intelligence Scale-Revised. Journal of Consulting and Clinical Psychology, 50(3), 415-418. https://doi.org/10.1037/0022-006x.50.3.415

Snyder, H. R., Miyake, A., \& Hankin, B. L. (2015). Advancing understanding of executive function impairments and psychopathology: Bridging the gap between clinical and cognitive approaches. Frontiers in Psychology, 6.

Spector, A., \& Biederman, I. (1976). Mental Set and Mental Shift Revisited. American Journal of Psychology, 89(4), 669-679.

Stirling, J., White, C., Lewis, S., Hopkins, R., Tantam, D., Huddy, A., \& Montague, L. (2003). Neurocognitive function and outcome in first-episode schizophrenia: A 10-year follow-up of an epidemiological cohort. Schizophrenia Research, 65, 75-86. https://doi.org/10.1016/S0920-9964(03)00014-8

Stroop, J. R. (1935). Studies of interference in serial verbal reactions. Journal of Experimental Psychology, 18(6), 643-662. https://doi.org/10.1037/h0054651

Suzuki, H., Gen, K., \& Inoue, Y. (2011). An unblinded comparison of the clinical and cognitive effects of switching from first-generation antipsychotics to aripiprazole, perospirone or olanzapine in patients with chronic schizophrenia. Progress in Neuro-Psychopharmacology and Biological Psychiatry, 35(1), 161-168. https://doi.org/10.1016/j.pnpbp.2010.10.021

Szöke, A., Schürhoff, F., Mathieu, F., Meary, A., Ionescu, S., \& Leboyer, M. (2005). Tests of executive functions in first-degree relatives of schizophrenic patients: A meta-analysis. Psychological Medicine, 35(6), 771-782. https://doi.org/10.1017/S0033291704003460

Taconnat, L., Raz, N., Toczé, C., Bouazzaoui, B., Sauzéon, H., Fay, S., \& Isingrini, M. (2009). Ageing and organisation strategies in free recall: The role of cognitive flexibility. European Journal of Cognitive Psychology, 21(2-3), 347-365. https://doi.org/10.1080/09541440802296413

Teipel, S. J., Meindl, T., Wagner, M., Stieltjes, B., Reuter, S., Hauenstein, K. H., ... Hampel, H. 

(2010). Longitudinal changes in fiber tract integrity in healthy aging and mild cognitive impairment: A DTI follow-up study. Journal of Alzheimer's Disease, 22(2), 507-522. https://doi.org/10.3233/JAD-2010-100234

Troyer, A. K. (2001). Improving memory knowledge, satisfaction, and functioning via an education and intervention program for older adults. Aging, Neuropsychology, and Cognition, 8(4), 256-268. https://doi.org/10.1076/anec.8.4.256.5642

Tyburski, E., Sokołowski, A., Cheć, M., Pełka-Wysiecka, J., \& Samochowiec, A. (2015). Neuropsychological characteristics of verbal and non-verbal fluency in schizophrenia patients. Archives of Psychiatric Nursing, 29(1), 33-38. https://doi.org/10.1016/j.apnu.2014.09.009

Tyson, P. J., Laws, K. R., Roberts, K. H., \& Mortimer, A. M. (2004). Stability of set-shifting and planning abilities in patients with schizophrenia. Psychiatry Research, 129(3), 229-239. https://doi.org/10.1016/j.psychres.2004.09.007

Van Assche, L., Morrens, M., Luyten, P., Van de Ven, L., \& Vandenbulcke, M. (2017). The neuropsychology and neurobiology of late-onset schizophrenia and very-late-onset schizophrenia-like psychosis: A critical review. Neuroscience and Biobehavioral Reviews, 83(April), 604-621. https://doi.org/10.1016/j.neubiorev.2017.08.024

Verhaeghen, P., \& Cerella, J. (2002). Aging, executive control, and attention: a review of metaanalyses. Neuroscience \& Biobehavioral Reviews, 26(7), 849-857. https://doi.org/10.1016/S0149-7634(02)00071-4

Vermeulen, J. M., Schirmbeck, F., Blankers, M., Van Tricht, M., Bruggeman, R., Van Den Brink, W., ... Van Winkel, R. (2018). Association between smoking behavior and cognitive functioning in patients with psychosis, siblings, and healthy control subjects: Results from a prospective 6-year follow-up study. American Journal of Psychiatry, 175(11), 1121-1128. https://doi.org/10.1176/appi.ajp.2018.18010069

Wagner, G., De la Cruz, F., Schachtzabel, C., Güllmar, D., Schultz, C. C., Schlösser, R. G., ... Koch, K. (2015). Structural and functional dysconnectivity of thefronto-thalamic system in schizophrenia: ADCM-DTI study. Cortex, 66, 35-45. https://doi.org/10.1016/j.cortex.2015.02.004

Westerhausen, R., Kompus, K., \& Hugdahl, K. (2011). Impaired cognitive inhibition in schizophrenia: A meta-analysis of the Stroop interference effect. Schizophrenia Research, 133, 172-181. https://doi.org/10.1016/j.schres.2011.08.025

Wilmsmeier, A., Ohrmann, P., Suslow, T., Siegmund, A., Koelkebeck, K., Rothermundt, M., ... Pedersen, A. (2010). Neural correlates of set-shifting: Decomposing executive functions in 
Wilson, R. S., Bennett, D. A., Bienias, J. L., de Leon, C. F. M., Morris, M. C., \& Evans, D. A. (2003). Cognitive activity and cognitive decline in a biracial community population. Neurology, 61(6), 812-816. https://doi.org/10.1212/01.WNL.0000083989.44027.05

Wongupparaj, P., Kumari, V., \& Morris, R. G. (2015). Executive function processes mediate the impact of working memory impairment on intelligence in schizophrenia. European Psychiatry, 30(1), 1-7. https://doi.org/10.1016/j.eurpsy.2014.06.001

Woodward, N. D., Purdon, S. E., Meltzer, H. Y., \& Zald, D. H. (2005). A meta-analysis of neuropsychological change to clozapine, olanzapine, quetiapine, and risperidone in schizophrenia. International Journal of Neuropsychopharmacology, 8(3), 457-472. https://doi.org/10.1017/S146114570500516X

Wykes, T., Reeder, C., Landau, S., Everitt, B., Knapp, M., Patel, A., ... Romeo, R. (2007). Cognitive remediation therapy in schizophrenia : Randomised controlled trial. British Journal of Psychiatry, 421-427. https://doi.org/10.1192/bjp.bp.106.026575

Wykes, T., Reeder, C., Landau, S., Matthiasson, P., Haworth, E., \& Hutchinson, C. (2009). Does age matter? Effects of cognitive rehabilitation across the age span. Schizophrenia Research, 113, 252-258. https://doi.org/10.1016/j.schres.2009.05.025

Zanelli, J., Reichenberg, A., Morgan, K., Fearon, P., Kravariti, E., Dazzan, P., .. Murray, R. M. (2010). Specific and generalized neuropsychological deficits: A comparison of patients with various first-episode psychosis presentations. American Journal of Psychiatry, 167(1), 7885. https://doi.org/10.1176/appi.ajp.2009.09010118

Zierhut, K. C., Schulte-Kemna, A., Kaufmann, J., Steiner, J., Bogerts, B., \& Schiltz, K. (2013). Distinct structural alterations independently contributing to working memory deficits and symptomatology in paranoid schizophrenia. Cortex, 49(4), 1063-1072. https://doi.org/10.1016/j.cortex.2012.08.027

Zigmond, A. S., \& Snaith, R. P. (1983). The Hospital Anxiety and Depression Scale. Acta Psychiatrica Scandinavica, 67(6), 361-370. https://doi.org/10.1111/j.16000447.1983.tb09716.x 
894

895

896 